\title{
Responsible innovation in human germline gene editing: Background document to the recommendations of ESHG and ESHRE
}

\author{
Guido De Wert ${ }^{1}$ - Björn Heindryckx ${ }^{2}$ - Guido Pennings ${ }^{3}$ - Angus Clarke $\mathbb{D}^{4}$ • Ursula Eichenlaub-Ritter ${ }^{5}$. \\ Carla G. van $\mathrm{El}^{6}$. Francesca Forzano ${ }^{7}$ - Mariëtte Goddijn ${ }^{8}$. Heidi C. Howard ${ }^{9}$. Dragica Radojkovic ${ }^{10}$. \\ Emmanuelle Rial-Sebbag ${ }^{11} \cdot$ Wybo Dondorp ${ }^{1}{ }^{1} \cdot$ Basil C. Tarlatzis ${ }^{12}$. \\ Martina C. Cornel $\mathbb{D}^{6}$ On behalf of the European Society of Human Genetics and the European Society of Human \\ Reproduction and Embryology
}

Received: 23 August 2017 / Accepted: 18 November 2017 / Published online: 12 January 2018

(c) The Author(s) 2018. This article is published with open access

\begin{abstract}
Technological developments in gene editing raise high expectations for clinical applications, including editing of the germline. The European Society of Human Reproduction and Embryology (ESHRE) and the European Society of Human Genetics (ESHG) together developed a Background document and Recommendations to inform and stimulate ongoing societal debates. This document provides the background to the Recommendations. Germline gene editing is currently not allowed in many countries. This makes clinical applications in these countries impossible now, even if germline gene editing would become safe and effective. What were the arguments behind this legislation, and are they still convincing? If a technique could help to avoid serious genetic disorders, in a safe and effective way, would this be a reason to reconsider earlier standpoints? This Background document summarizes the scientific developments and expectations regarding germline gene editing, legal regulations at the European level, and ethics for three different settings (basic research, preclinical research and clinical applications). In ethical terms, we argue that the deontological objections (e.g., gene editing goes against nature) do not seem convincing while consequentialist objections (e.g., safety for the children thus conceived and following generations) require research, not all of which is allowed in the current legal situation in European countries. Development of this Background document and Recommendations reflects the responsibility to help society understand and debate the full range of possible implications of the new technologies, and to contribute to regulations that are adapted to the dynamics of the field while taking account of ethical considerations and societal concerns.
\end{abstract}

\section{Introduction}

Gene editing has attracted major attention from scientists and the media in recent years. While scientists in laboratories witness a revolution, much of the conversation about clustered regularly interspaced short palindromic repeatsCas9 (CRISPR/Cas9) has revolved around its potential for treating disease or editing the genes of human embryos [1]. Unlike experiments with zinc-finger nucleases and transcription activator-like effector-based nucleases (TALEN), the CRISPR/Cas9 system turned out to have unprecedented ease and finesse. Treatment of cancer patients using gene

Guido De Wert

g.dewert@maastrichtuniversity.nl

Extended author information available on the last page of the article editing has started [2,3]. Expectations are that many more potential applications will follow. Ongoing trials are reported for thalassemia and sickle cell disease, mucopolysaccharidosis I and II, and haemophilia B, among others (www.clinicaltrials.gov). These trials are preparing treatment possibilities, for instance by studying treatment at the human cellular level. Somatic gene editing may prove to be a game changer not only in the treatment of a whole range of serious hereditary, particularly Mendelian, disorders, but also in the treatment of cancer and infectious diseases. Gene editing is a medicinal product for human use, where regulations apply. The European Medicines Authority (EMA) that oversees access of medicinal products to the market, including advanced therapy medicinal products, has identified scientific and regulatory guidance on gene editing as an issue for its future agenda [4]. Ethical, legal and societal issues for somatic gene editing include safety and 
accessibility, and meaningful stakeholder engagement, education, and dialogue must be organized [5]. However, if somatic gene editing became safe and cheap, there would be few other ethical or legal objections left.

For editing the genes of human embryos the situation is different. The prospect of technologies coming available that would allow making changes in the (human) germline has been heavily debated in recent decades, and in many countries germline interventions have been prohibited, sometimes even accompanied by criminal sanctions [6]. In previous decades, legislation has been developed not allowing changes in the human germline, including the Convention for the protection of human rights and dignity of the human being with regard to the application of biology and medicine, often referred to as the Oviedo Convention [7] and the recent Clinical Trials Regulation (No. 536/2014) [8]. What were the arguments behind this legislation, and do these still apply? If a technique can help to avoid serious genetic disorders, in a safe and effective way, would this be a reason to reconsider earlier standpoints? Discussion with relevant stakeholders is needed, including professional health care workers, patients, citizens, and legal and ethical experts. Globally and also within Europe there is diversity, as several countries have not ratified the Oviedo Convention, which prohibits any (human) germline modification. Meanwhile in the USA a summit was organized in December 2015, that brought together scientists, ethicists, legal experts and patient groups from around the world [9]. The recent report published by the National Academies of Sciences, Engineering, and Medicine argues that 'Scientists should be permitted to modify human embryos destined for implantation in the womb to eliminate devastating genetic diseases such as sickle-cell anaemia or cystic fibrosis-once gene-editing techniques advance sufficiently for use in people and proper restrictions are in place' [10, 11]. Furthermore, altering human embryos in the laboratory for the sake of basic research should be acceptable. The report of the National Academies [11] outlines strict limits under which scientists could proceed in the future. It recommends restricting the technique to severe medical conditions for which no other treatment exists.

We thus witness that initiatives have been taken worldwide to exchange views about responsible innovation using human gene editing, including germline gene editing (GLGE). Modifications in the germline genome have been considered a much more sensitive issue than somatic gene editing. The recent scientific advances rekindle ethical and policy questions surrounding the acceptability of germline modification [6]. While in the past some may have considered the question of acceptability of germline gene modification not urgent because it was technically impossible, the current scientific developments make the issue more urgent than ever. Also, the international differences and potential for cross-border movements of patients make societal debate urgent.

The European Society of Human Genetics (ESHG) and the European Society of Human Reproduction and Embryology (ESHRE) consider it to be their professional responsibility to contribute to further discussion on GLGE. As in earlier collaboration between the ESHG and other professional societies, a Background document and Recommendations have been developed. The current text is the Background document. Its aim is to inform and stimulate ongoing societal debate and serve as a background for ESHG/ESHRE Recommendations. Drafts of the Background document and Recommendations were prepared by a joint writing group. These were discussed in both committees and in a joint meeting of the two societies on September 20, 2016. A draft of the recommendations was online on the ESHG and the ESHRE website from october 17 until December 2, 2016 forming the backdrop for its presentation at the American Society of Human Genetics meeting in Vancouver. This Background document together with the Recommendations were subsequently posted online on the ESHG and the ESHRE websites to solicit comments from experts and the membership of both the ESHG and ESHRE from April 3 until May 8, 2017. The authors integrated the suggestions to the background document where appropriate. The endorsed recommendations are available in the European Journal of Human Genetics [12] and in Human Reproduction Open [13].

\section{Scientific developments and expectations regarding GLGE}

It is first of all important to distinguish the target population of cells on which gene editing can be performed, being somatic cells, pluripotent stem cells (PSC) or the germ cells. Gene modifications in somatic cells, or mostly in PSC, are intended for the patients themselves and would not usually be transmitted to the progeny. In contrast, gene editing in the germline, and in some cases in PSC that become differentiated to germ cells in vitro, would change the individual's hereditary genetic profile and would thus be transmitted to future generations (Fig. 1) [14]. Besides the gene editing in nuclear DNA, also experiments aiming at gene editing in mitochondrial DNA (mtDNA) can be considered as gene editing in the germline. Like editing nuclear DNA, transmission of genetically edited mtDNA can be used to eliminate mutant mitochondria or alter the mtDNA and be transmitted to offspring. The use of donor cytoplasm to replace one set of mitochondria with a different set is a distinct method of germline modification that does not involve gene editing technologies. In theory, gene-edited somatic cells could be used for somatic cell nuclear 
transfer (SCNT) aimed at producing genetically modified descendants [15]. There is a worldwide moratorium on human reproductive cloning, so the latter use of SCNT technology is not considered ethically acceptable in humans at present.

As for the stage at which germ line modifications could be introduced, scientists envisage that this would be carried out at the level of the germ cell or its progenitor cells during gametogenesis in vitro (Fig. 1) [14], or later at the stage of the fertilized oocyte (zygote) or in the early embryo. State of the art literature for these possible germline modifications is discussed below.

\subsection{Gene editing in zygotes or pre-implantation embryos}

For germ-line modifications in experimental settings the genomic editing system is mostly injected into the cytoplasm or pronuclei of zygotes or into pre-implantation embryos, after which genetic screening is used to select the embryos with a corrected genomic pattern in the absence of detectable off-target genetic modifications. Should this turn out to be safe and effective, then similar applications in the clinic are conceivable. Subsequently, prenatal testing using either cell-free foetal DNA from the pregnant woman's blood or one of the more invasive methods (chorionic villus sampling or amniocentesis), could in theory verify whether or not a foetus shows molecular or genomic mosaicism. Mosaic embryos arise as a result of inefficient cutting of the nucleases or inaccurate DNA repair before the embryo has reached the stage of cleavage. The pre-implantation embryo stage is generally not favoured for genome editing as it would most likely lead to a mosaic individual and possibly to more unforeseen detrimental effects. Various studies in different animal models have demonstrated the feasibility of gene editing in animals at the zygote stage [16-19]. The potential of the technology to prevent the onset of a genetic disorder in mice was demonstrated by the studies of $\mathrm{Wu}$ et al. [20] and Long et al. [21], respectively, for cataract and Duchenne muscular dystrophy. Also in non-human primates, microinjection of Cas9 or TALENs into zygotes led to the birth of targeted gene-modified offspring [22-24]. In mammalian zygotes, the efficiency of the correction of an indel in a single gene by TALENs or Cas 9 ranges from 0.5 to $40.9 \%$ per injected zygote [25]. Ran et al. [26] reported that the double nicking by RNA-guided CRISPR/Cas9 nickase treatment can lead to $80-100 \%$ efficiency in mouse blastocysts. Regarding gene modification in subsequent neonates, the efficiencies of indel and gene addition were $0-41.7 \%$ by TALENs or Cas9, and 1.7 and $3.0 \%$ by Cas9, respectively. In the targeted gene modifications, the efficiency is $2.0-6.0 \%$ in mouse offspring, coinciding with offtarget mutations [25].
In the human, researchers are restricted by the limited availability of embryos because of ethical and/or legal constraints. Most supernumerary ('spare') human embryos available for research will have progressed beyond the cleavage stage, giving rise to more mosaicism when genomic editing is attempted. Only in countries where the creation of embryos for the exclusive purpose of research is allowed could this technique be applied at earlier stages and with fresh oocytes/embryos. One alternative source would be oocytes that failed to be fertilized, which could then be fertilized or artificially activated and subsequently used for genomic editing for research purposes. Alternatively, abnormally fertilized zygotes (mostly 1 pronucleus (PN) or $3 \mathrm{PN}$ ) could be used, as was the case in two recent Chinese reports [27, 28]. Of the 86 injected 3PN human zygotes, four $(4.7 \%)$ contained the correct genetic material repaired through non-homologous end joining (NHEJ) [27]. The genomic edited embryos were mosaic, similar to findings in other model systems [29-31]. In addition, a substantial number of 'off-target' mutations were observed, either caused by the inefficient CRISPR/Cas9 complex acting in other parts of the genome and/or the abnormal triploid chromosomal content originating from the abnormally fertilized 3PN zygotes. Also in another more recent study [28], the efficiency of homology directed repair (HDR) of the CCR5 532 allele was low, and the edited embryos originating from 3PN zygotes were mosaic. It has to be noted that neither of the studies in the human used the most up-todate CRISPR/Cas9 methods [27, 28]. Recently, some alternative methods used in mice significantly increased the efficiency of genomic editing technology while, at the same time eliminating mosaicism in reconstructed embryos.

Even if ethical/legal barriers for embryo research could be removed and the supply of zygotes or embryos was fully resolved, significant technical hurdles would remain. These need to be tackled to gain control of the genotype of both alleles in a viable embryo. For example, microinjection of the genomic tool machinery into zygotes only (not embryos) is a technically demanding and labour-intensive procedure, which can hamper subsequent embryo development. As an alternative, a simple electroporation-based strategy to deliver Cas9/sgRNA ribonucleoproteins into mouse zygotes was proposed, with $100 \%$ efficiency for in vivo genome editing and no decrease in embryo viability [32]. A similar technology was recently used by Hashimoto et al. [33], who claimed that electroporation of the Cas9 protein/sgRNA into early pronuclear zygotes generates nonmosaic embryos in the mouse. The key to success was performing the electroporation into the fertilized zygotes very early, enabling the genomic editing to occur before the first replication (S-phase) of the mouse genomic DNA.

In a recent breakthrough article that appeared after the round of discussion in the professional Societies as 


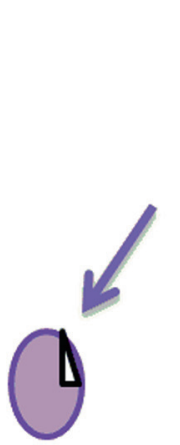

Testis biopsy

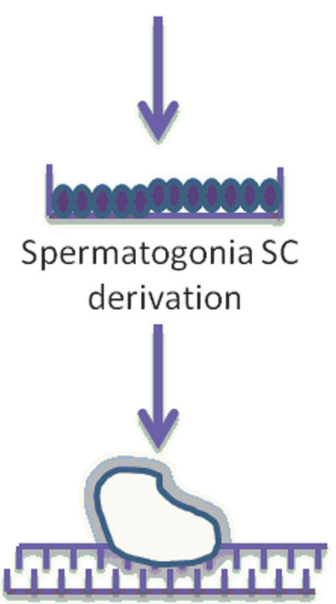

CRISPR/Cas9 editing in spermatogonia SC

Gamete differentiation

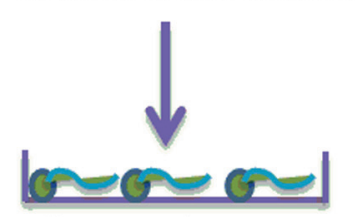

Corrected sperm

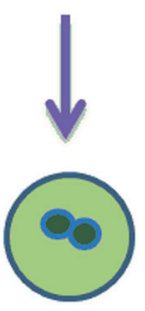

ICSI

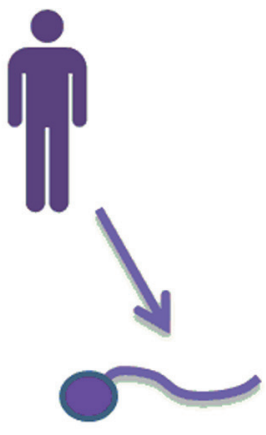

Affected sperm

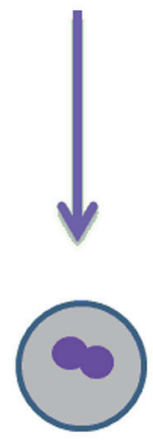

IVF/ICSI
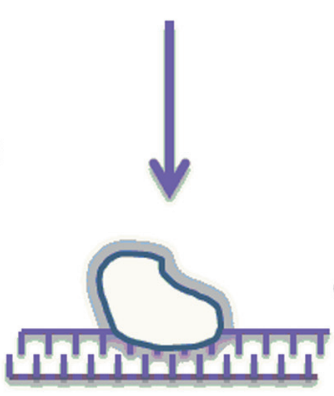

CRISPR/Cas9 editing in embryo

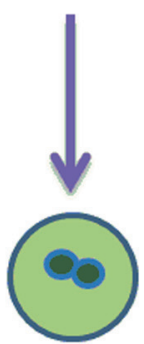

Corrected embryo
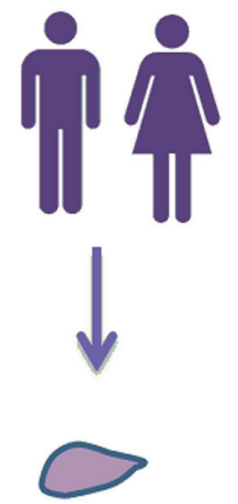

Skin biopsy

Conventional stimulation

Affected oocyte

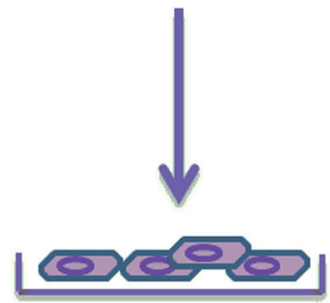

Reprogramming

iPS derivation

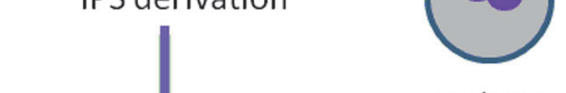

IVF/ICSI

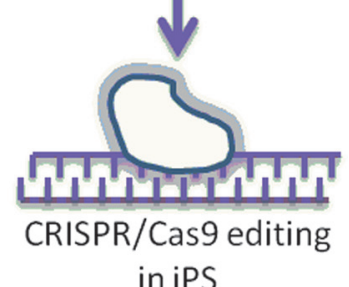

Gamete differentiation
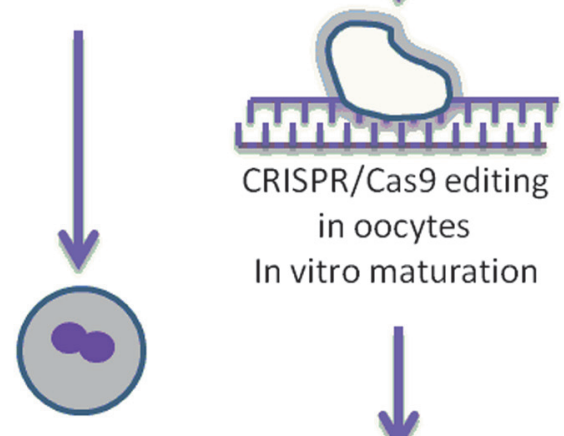

CRISPR/Cas9 editing

in oocytes

In vitro maturation

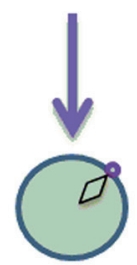

Corrected MII oocyte

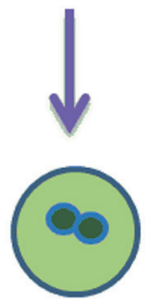

ICSI

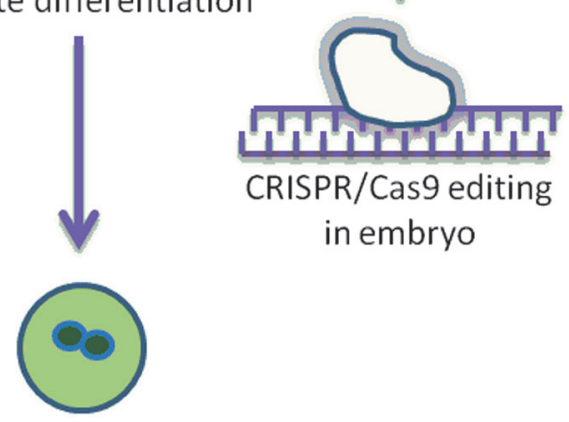

ICSI

Corrected embryo

Fig. 1 Overview of the possible strategies to perform genome editing in the germline in men and women. SC stem cell, MII metaphase-II, GV germinal vesicle, iPS induced pluripotent stem cells, CRISPR clustered regularly interspaced short palindromic repeats. (Republished with permission from Vassena et al. [14].) 
discussed in the Introduction of this document, the group of Mitalipov [34] described the correction of a heterozygous mutation present in sperm by highly efficient genomic editing using CRISPR/Cas9 based targeting in human embryos. Interestingly, the double-strand breaks were predominantly repaired by the wild-type homologous maternal gene in the oocyte instead of the synthetic DNA that was supplemented during injection. The highest efficiency, with avoidance of mosaicism in the resulting edited embryos and the absence of off-targets, was achieved when the CRISPR/ Cas9 tool was injected at the time of fertilization, when injecting the mutated sperm. This was not the case when traditional genomic editing was performed at the zygote stage, the latter resulting in lower efficiency of correctly edited embryos and the presence of mosaicism.

Next, identifying genome-wide off-target sites is important to avoid and prevent, or at least reduce, false positive and false negative sites; concomitantly, accurate methods to measure off-target mutation frequencies have to be developed. Current genome wide sequencing platforms often cannot detect off-target sites at frequencies below $0.1 \%$. Nowadays next-generation sequencing (NGS) technologies have been successfully applied to reveal off-target genetic modifications after application of, for example, CRISPR/ Cas technology. Through whole genome sequencing (WGS), thousands to millions of sequencing reactions can be performed in parallel allowing genome wide screening more rapidly in a high throughput manner. The data can be analysed by the CRISPR Genome Analyzer platform (CRISPR-GA), currently a popular bio-informatics tool that provides information on size and location of indels and on the efficiency of NHEJ and HDR events. A recently developed, easy-to-use bioinformatics tool for batch analysis of NGS-generated genome editing data allows detection of indel mutations and other precise genome editing events as well as rapid calculation of the corresponding mutagenesis efficiencies [35]. This progress in off-target detection will help ensure that the CRISPR/Cas or similar gene editing technologies work in a safe and accurate manner.

\subsection{Gene editing of male and female germ cells}

An alternative to the zygote/embryo approach is to perform gene modifications during early gametogenesis. In this manner, growing immature oocytes or sperm or even precursor cells (primordial germ cells) can be gene targeted by using the CRISPR/Cas system, producing genetically corrected mature sperm or oocytes that subsequently can be used for ART. In the male germ cell line, spermatogonial stem cells (SSC) can be harvested more and more efficiently, and in vitro culture systems are being developed, also in the human, and optimized for efficient production of sperm in vitro. So far, animal models have indicated that SSC can be propagated as clones in culture and then transplanted back into the testis to generate mature and functional sperm [36]. So a potential strategy would be to select SSC clones that have undergone correct genomic editing and are free from off-target mutations. These can then be transplanted to undergo final maturation in vivo. Alternatively, the gene edited SSC can be directly differentiated in vitro to mature gene-corrected sperm, to be used for IVF. Still, optimisation of in vitro culture systems is warranted, especially in the human, so that gene editing technologies can be employed safely and with high efficiency.

In the female germ line, the oocyte is more easily accessible for genetic manipulation, but currently technical hurdles remain, such as the small number of oocytes that are available [14]. It has been suggested that oogonia-like stem cells could be harvested, cultured and expanded followed by culture in vitro to the mature metaphase II stage [37]. However, there is still controversy over the existence of such oocyte precursor cells in the female and the efficiency at which mature, developmentally competent oocytes can be derived from them.

A last possibility is to produce gametes in vitro from PSC. These PSC could either be human embryonic stem cells, made genetically identical to the prospective parent by somatic cell nuclear transfer, or PSC obtained through the direct reprogramming of differentiated cells (induced PSC, iPSC). One advantage of this approach is that PSC in culture are easy to manipulate to correct genetic abnormalities. PSCs can be grown easily in bulk amounts, especially in the naive state of pluripotency [38-40], and sustain single cell passaging, which makes them an ideal source for gene editing experiments with the CRISPR/Cas system. Ultimately, these PSC have to be differentiated towards oocytes or sperm that would contain the genetically corrected information and can thus be used in ART. PSC-derived gametes were successfully established in mice [41, 42], although this approach still required a maturation step in vivo in order to obtain functional oocytes or sperm. Nowadays, full differentiation of mouse embryonic stem cells into mature functional sperm [43] and oocytes [44] has been achieved in vitro. If this strategy proves successful in the human, despite the system's greater complexity, genomic editing might well be successfully applied to produce gene edited gametes and offspring in the future.

\subsection{Genome editing in the mtDNA}

Another form of DNA modification, albeit not in the nuclear DNA, involves the transfer of donor mitochondria containing mtDNA from one cell to another [45], or the use of genomic editing in the mtDNA to eliminate mutant 
mitochondria or at least change the heteroplasmy ratio (the proportion of abnormal copies of mtDNA) in progeny, for example, in order to rescue deficiencies in oxidative phosphorylation [46-48]. This mtDNA modification (whether achieved by mitochondrial replacement technique (MRT) or by editing of the original mtDNA) should be considered as a genome-altering procedure, which can be passed on to future generations. Note that in MRT the genome is not edited, and different safety and efficacy considerations apply when compared to gene editing. In theory, mtDNA modification can also cause heteroplasmy, containing two or more sets of genetically different mtDNA in the resulting oocytes, as a result of an incomplete elimination of mitochondria with mutant mtDNA or of undetected off-target effects (genetic or epigenetic). More recently, MRT has been proposed to overcome maternal transmission of serious mtDNA disorders. For nuclear transfer, the nucleus of an oocyte from a patient with a known mtDNA mutation is transferred into a healthy enucleated donor oocyte (spindle transfer) or zygote (pronucleus transfer) to overcome mtDNA disorders. The safety and efficacy of this nuclear transfer technology has been mostly studied in animal models but has also been shown to cause little if any heteroplasmy in human tripronuclear embryos [45]. These nuclear transfer technologies appear to be efficient in terms of embryonic development and safe in terms of minimal mtDNA carryover [45, 49]. In April 2016, the first child resulting from maternal spindle transfer was born [50]. The mother was an asymptomatic carrier of a mitochondrial mutation that caused Leigh syndrome, a fatal neurological disorder. The child, who has $1 \%$ of its mother's mtDNA, was healthy at 3 months, although it is not known if any abnormality might appear later on. The use of gene editing technology appears also to correct mtDNA disorders. In a heteroplasmic mouse model containing two genetic backgrounds of mtDNA, selective prevention of germline transmission of one kind of mtDNA has been accomplished using either mitochondria-targeted restriction endonucleases or TALENs [51]. CRISPR/Cas9 has also been successfully employed in mtDNA editing, and mitoCas9a (a new version of the enzyme Cas9) with specific localization to the mitochondria has been developed [47].

\subsection{Rationale for germ cell genomic editing}

The following lines of basic research involving genome editing technology in the germline can be considered: addressing fundamental questions of early human and animal developmental biology; gaining information to understand and improve the technique and safety of genome editing itself; and engineering specific disease-related mutations in embryos used as experimental animal models, to subsequently analyse the genome edited offspring or derivative PSC for the development of drugs or other treatments for disease. These research applications are important for gaining more insight into basic developmental biology regardless of any potential future human reproductive GLGE. So far, most of our knowledge of early embryonic development is based on animal models, especially the mouse. However, recent studies have shown that the molecular pathways involved during early embryonic development differ between animal models and humans. For example, the SOX17 gene was recently demonstrated, by the use of human embryonic stem cells, to be crucial for the formation of primordial germ cells in the human, while this is not the case in the mouse [52]. Accordingly, in the UK, a license was approved in 2016 for Dr Niakan (The Francis Crick Institute) [53] to study early lineage segregations in humans. This will hopefully allow us to understand the molecular pathways involved in early embryonic development and differentiation, and might, for example, also be beneficial for disentangling complex or poorly understood causes of infertility (such as implantation failure) and developing novel routes for treatments.

Germline editing technology could potentially also be applied to other infertility related treatments. For example, it has been shown that mutations in the phospholipase $\mathrm{C}$ zeta $(P L C z)$ gene, which is responsible for successful oocyte activation, can lead to failed fertilization after ICSI [54]. Two point mutations in the exons of the $P L C z$ gene were identified, one paternally, and one maternally inherited [55]. These might be corrected by genomic editing during spermatogenesis of the male patient or following the strategy of first deriving patient specific stem cells, followed by gene correction in stem cells and finally differentiation towards functional sperm containing the corrected $P L C z$ gene and function. Similarly, variants in the polo-like kinase 4 gene (PLK4) which predispose to embryonic aneuploidy [56] might be corrected in the female germ line and thereby increase the chance of obtaining more euploid embryos for implantation and conception of a genetically normal child.

\section{Legal regulations regarding GLGE (European level)}

The focus of this paragraph is on transnational, in particular European, regulation of embryo research and germline genetic modification. The international regulatory landscape for developing GLGE has been summarized by Araki and Ishii [25] and Isasi et al.[6].

\subsection{Embryo research}

An important element in this landscape is the variation of national legislation governing embryo research among 
European countries. On the one side of the spectrum, some countries (e.g., Austria, Germany, Italy) forbid all research using human embryos (only excepting 'non-instrumentalizing' research aimed at benefitting the embryo in question). On the other side, a limited number of countries (e.g., the UK, Belgium and Sweden) allow the creation of human embryos for research purposes. In between, are countries (e.g., France, Portugal, the Netherlands) allowing human embryo research using supernumerary (left-over or spare) IVF-embryos, while explicitly forbidding the creation of human embryos for purposes other than pregnancy.

At the European level, an important document is the Convention on Human Rights and Biomedicine (Oviedo Convention) of the Council of Europe [7] that has been ratified by 29 states. Article 18, part 2, of this Convention forbids the creation of human embryos for research purposes. As ratification requires further national legislation by the ratifying partners to be in line with the Convention, countries having ratified this document are bound to maintain this ban.

To the extent that human embryo research aimed at developing GLGE requires normal one-cell stage embryos, these embryos will have to be created specifically for the purpose. As a consequence, this research can be carried out in a limited number of European countries, depending on further regulatory conditions also with regard to accepted purposes. Should the research move to investigating GLGE in blastomeres, supernumerary IVF-embryos could be used in countries allowing research with those embryos, depending again on further conditions. Given the ethical sensitivity both of creating embryos for research and of asking women to donate the necessary oocytes, the principle of subsidiarity (as for instance laid down in the Belgian Embryos Act, Article 4 part 1) requires that no human embryos should be created for research that can be performed equally well with spare embryos [57].

\subsection{Germline genetic modification}

The scope for future clinical, reproductive application of GLGE will depend on legislation conditionally allowing, rather than categorically forbidding, procedures aimed at modifying the human germline. Whereas most countries (based on recent surveys) currently prohibit germline modification, many of the concepts used in relevant legal documents are ill-defined and ambiguous, including the distinction between research and clinical applications and basic definitions [6, 25]. For instance, whereas the Belgian Embryos Act does not contain a categorical ban on germline modification, it contains a provision (Article 5 part 4) forbidding 'research or treatment with a eugenic purpose, that is: aiming at the selection or enhancement of non-pathologic genetic traits of the human species' [57].
Here again, the Convention on Human Rights and Biomedicine (Oviedo Convention) of the Council of Europe is a key document [7]. Article 13 states that "An intervention seeking to modify the human genome may only be undertaken for preventive, diagnostic or therapeutic purposes and only if its aim is not to introduce any modification in the genome of any descendants".

There has been much debate about whether MRT aimed at helping women at risk of transmitting a mitochondrial disorder to have healthy children should be regarded as a form of germline modification [58-60]. MRT refers to procedures in which the pronuclei, meiotic spindle or polar bodies of the prospective mother's oocytes are transferred to an enucleated donor oocyte [61]. While UK legislation prohibits clinical applications of germline modification, this ban does not apply to MRT, given recent regulations specifically allowing the reproductive use of this technology subject to some conditions. As these regulations specify the method used in MRT (germline transplantation rather than editing), this has no implications for a potential use of GLGE of mtDNA.

The legal context is different in the Netherlands, where legislation was also adapted to allow for MRT [62]. As this was achieved by limiting the ban on reproductive germline modification in the 2002 Dutch Embryo Act [63] to the intentional modification of the nuclear DNA (Article 24g), it would seem that not only MRT, but also clinical GLGE of mtDNA is beyond the scope of the legal prohibition of germline modification in the Netherlands. Whether the legislator would have accepted this implication is an open question as GLGE was not yet available when the Act was drafted.

These are only a few out of many examples of how legislation in this field tends to lag behind the dynamics of the very technologies that it means to regulate [6]. Considering the dynamics of the scientific discoveries and medical developments it is relevant to reflect on what the arguments were behind such legislation. Do these still apply? If a technique can help to avoid serious genetic disorders, in a safe and effective way, would this be a reason to reconsider earlier standpoints? It should be considered to structure a legal framework that could be more flexible and promptly reactive to the evolution of the technologies and possibilities, under an appropriate societal oversight.

From an ethical point of view, scientists and clinicians must respect the legal and regulatory framework in their country. They also have an important responsibility to help society understand and debate the full range of possible implications of the new technologies, and to contribute to regulations that are adapted to the dynamics of the field while taking account of ethical considerations and societal concerns. As the European professional and scientific organizations most comprehensively involved in the development of GLGE technology, ESHRE and the ESHG are well placed and willing to take up this responsibility. 


\section{Ethics}

While the scenario of future genetic modification in the human germline has been a topic of debate for decades, recent developments in genome editing give a new impetus to ethical and societal discussions. For an adequate debate and reflection, it is important to make a distinction between (non-reproductive) basic GLGE-research, (non-reproductive) preclinical GLGE-research, and possible future human reproductive, clinical, GLGE, taking account of both moral concerns and objections, and possible scientific and clinical advantages of GLGE. Although the distinction between basic and preclinical research is important, there may well be an overlap between these types of research. For instance, basic research may aim at improving the precision of the technology, thereby lowering the risk of off-target effects and enabling future clinical GLGE.

\subsection{Basic research}

\subsubsection{Possible advantages}

A general advantage of basic research is that it will generate new scientific knowledge, which may contribute to improving human health and welfare. GLGE-linked basic research mostly regards the study of fundamental questions regarding human embryology and the methods applied in gene editing. A good example concerns the plans of researchers in, for example, the UK to study genetic factors linked with early embryo development, implantation and problems with both development and implantation. This may help to improve the success rate of assisted reproduction.

\subsubsection{Objections and concerns}

There are different types of ethical objections, both deontological and consequentialist, to basic research regarding human GLGE, especially insofar as this involves the research use of human embryos.

4.1.2.1 Deontological objections and concerns Questioning the 'instrumentalizing' use of human embryos in basic GLGE research relates to a wider legal and ethical debate on embryo research that has been evolving over more than three decades worldwide. Critics of 'instrumentalizing' embryo research mostly argue that such research is at odds with the proclaimed high, even 'person-like', status of the embryo.

This view is, however, widely contested [64-66]. Although the moral status of the early embryo is significant, there is wide support, both in secular ethics and in various religions, for the view that at least the early embryo has a lower moral status than a foetus, and much lower than a child and adult. For that reason, legal regulations and ethical principles and guidelines regarding medical research with human subjects, aimed at protecting research participants from serious harm, do not apply to early (preimplantation) embryos in vitro (especially if these embryos will not be transferred). (The arguments for this view differ and relate, for example, to the lack of sentience and cognitive functions, and/or the lack of so-called 'ontological individuality'; after all, the early embryo may still split, or different embryos may combine to build one single embryo.) Against this background, many countries have accepted a regulatory approach which leaves room for at least some embryo research on (more or less strict) conditions, including proportionality and subsidiarity (see section 3.1).

Parthenotic embryos ('parthenotes') and 3PN embryos can and have been used as alternatives for 'normal' embryos in research, including basic research on GLGE (see section 2). These alternatives may be used and preferred for different reasons, including the wish to mitigate or even completely avoid the controversy regarding embryo research. Parthenotes and 3PN embryos are regularly not considered to be embryos as they lack the potential to develop into a (viable) child (a condition that is frequently part of the definition of an embryo). Or alternatively, they are seen as embryos with a somewhat lower status in view of this diminished potential [67, 68]. Postponing a stance on the possible merits of these normative views, it is sufficient for the moment to state that the research use of parthenotes and 3PN embryos does not pre-empt the need to make use of normally fertilized oocytes for research, including GLGElinked research.

Most controversial is whether it would be ethically justified to not only make use of left-over or spare embryos, but also to create embryos specifically for research purposes, so-called'research embryos'. According to ESHRE, among others, there is no fundamental, decisive, ethical difference between the two [69]. After all, both the moral status and the fate of spare and research embryos are the same. Still, it is widely-and rightly-accepted that one should not engage in making embryos specifically for research if this research can be conducted by using spare embryos. While spare embryos may be useful for research, including some types of GLGE-linked research, research embryos are sometimes necessary. Most importantly, spare embryos conceived by conventional IVF/ICSI are simply not useful for safety-research regarding new (pre-conception or peri-conception) reproductive technologies. Examples include in vitro maturation (IVM) and stem-cell derived ('artificial') gametes. Likewise, the making of research embryos is necessary for (some types of) preclinical GLGE research, especially if such research aims at 
studying the effects of GLGE applied in either gametes or very early embryos, or when such research requires specific genotypes, not available in spare embryos.

Most jurisdictions accept a time-limit regarding embryo research of 14 days. Recent research suggests that it will become possible to grow human embryos in vitro for longer than 2 weeks. Research beyond 14 days may increase the value and relevance of both basic and preclinical safety research. This may hold true for GLGElinked research as well. As a consequence, a (renewed) discussion about the ethics of a possible extension of the time-limit has started [70, 71]. Questions include: what, precisely, are the arguments in favour of the present 14day limit? Are these arguments convincing or could a later time-limit be ethically and legally justified, and if so, what limit-and why? What about a slippery slope? Clearly, the time-limit regarding embryo research should be part of the agenda for further ethical and societal debate and reflection.

Another relevant item for the normative debate on research embryos is the position and protection of candidate donors of oocytes for research. Concerns regard both the autonomy and the welfare of oocyte donors. Among others, ESHRE recommended to impose conditions, in line with the regular safeguards to protect participants in research, aimed at minimizing the risk of pressure to donate and avoiding disproportionate medical risks and exploitation [65, 72]. Such conditions should also be taken into account in the context of non-reproductive GLGE research with research embryos. The future availability of surplus oocytes frozen (but no longer needed) for fertility preservation might eliminate or at least lower some of these risks and concerns.

A final deontological concern emerges with the possible use of WGS ('comprehensive' Preimplantation Genetic Screening (PGS)) of edited embryos, in the context of a trio-analysis, as a method to pre-clinically study and reduce possible off-target effects (iatrogenic damage) in edited embryos. This strategy would require specific informed consent from the providers of the spare embryos or gametes used. The central normative question raised by such screening would be how to respect the gamete or embryo providers' right (not) to know/(not) to be informed about any incidental findings (IFs) regarding their own genetic status. This question is not unique to such GLGE-linked research, as it also arises in the context of, for example, genomic research making use of human material in biobanks. Relevant guidelines for the responsible handling and communication of IFs can be found in recent literature and documents [73, 74].

\subsubsection{Consequentialist objection: the 'slippery slope' towards reproductive GLGE The slippery slope-argument}

against basic GLGE research presumes both that allowing such research will result in future reproductive applications (the empirical premise), and that such reproductive applications are ethically unjustified (the ethical premise). What about the strength of these premises: are these convincing?

Both premises are contested. With regard to the empirical premise, one may argue that reproductive applications of GLGE will not automatically follow-these could continue to be forbidden, as is the case now in most countries worldwide. In scrutinizing the empirical premise of the slippery slope-objection, it may be important to make a distinction between basic and pre-clinical GLGE-research (even though the demarcation is not sharp) as pre-clinical research may be more vulnerable to this slippery slope objection than basic research. For that reason, this objection will be elaborated in that context (see section 4.2).

\subsection{Preclinical research}

Pre-clinical research aims at assessing the effectiveness and safety of possible future clinical/reproductive GLGE.

\subsubsection{Possible advantages}

The general value of pre-clinical research has been acknowledged in the normative framework for responsible innovation in assisted reproduction and related technologies (ART), as proposed by, amongst others, the Health Council of the Netherlands [65] and (the Task Force on Ethics and Law of) ESHRE [75]. While new, experimental, reproductive technologies are often introduced in the clinic without proper pre-clinical research, including safety studies, this framework stipulates that pre-clinical research, primarily aimed at avoiding or at least reducing health risks for possible future children thus conceived, should be performed as much as is reasonably possible. Such research could involve using cells/tissues, animals, and human embryos in vitro (on strict conditions) [65, 75]. The ethical rationale of pre-clinical safety research is obvious: one should rather experiment on early embryos in vitro than on future children thus conceived and prospective parents, especially mothers. As Anne McLaren eloquently stated: to refrain from adequate pre-clinical safety studies is like "making the first test of a new aircraft-guidance system on a crowded Boeing 747" [76]. This framework would be relevant for any proposed future clinical applications of GLGE.

\subsubsection{Objections and concerns}

4.2.2.1 Deontological objection If human embryos are used in preclinical research, such research, like basic 
research involving human embryos, is criticized because of the instrumental use of embryos. As indicated before, this criticism is based on a widely contested view on the moral status of the early human embryo (see section 4.1.2).

\subsubsection{Consequentialist objection: the slippery slope As} stated before (see section 4.1.2), pre-clinical GLGEresearch may be more vulnerable to the slippery slopeobjection than basic GLGE-research; the step from basic GLGE-research to clinical application of GLGE is much greater than the step from pre-clinical GLGE-research to clinical GLGE. After all, the whole idea of pre-clinical research is to study whether the conditions for sound clinical applications in terms of effectiveness and safety can be met. But crucially, the slippery slope's second, ethical, premise, namely that (any) reproductive GLGE is ethically unjustified, is not self-evident. In fact, there is wide disagreement regarding the ethics of possible clinical GLGE apart from safety-concerns. If one would consider, for example, principled, deontological, objections to clinical GLGE to be convincing (see section 4.1.2), then pre-clinical studies would not only be a complete waste (of money, energy and embryos), but also bring us dangerously close to the edge of the slope. And as long as it is unclear as to whether safe clinical GLGE could be morally justified, preclinical safety research can be easily dismissed as premature (and disproportional). But if only safety issues stand in the way of morally justified clinical GLGE, then, obviously, pre-clinical safety studies would be justified.

\subsection{Future reproductive human GLGE}

\subsubsection{Possible advantages}

GLGE could, if safe and effective, contribute to greater welfare, first and foremost in terms of health gains. Such GLGE could well be more effective than somatic editing when it comes to multi-organ disease, and have a further advantage because of its transgenerational or multigenerational effects. According to some commentators, GLGE may also have positive-but contested-effects in terms of enhancement (see below) [77].

Linked to this is the argument of respect for reproductive autonomy. People at high genetic risk of having a child affected with a serious disorder or handicap may feel more confident to reproduce or may see the editing as a prerequisite of reproduction [78]. Even though there are other reproductive options to avoid genetic disorders in future children, people may have reasons to prefer GLGE (see below).

Last, but not least, correcting disease-causing genes may be seen as promoting justice: increasing the equality of opportunity of every person. The natural unequal distribution of capabilities (through the genetic lottery) is corrected by modifying the genetic constitution of persons who received less than their fair share of capabilities [79].

\subsubsection{Objections and concerns}

Again, it may be helpful to distinguish different types of objections and concerns:

4.3.2.1 Deontological objections The deontological arguments against germline gene modification have been around for some decades. We will only discuss the more relevant ones and leave aside the general objections such as 'it is unnatural', 'playing God' etc. The main problem with several of the arguments is that they are very broad and would be applicable to many medical interventions that are (very) widely accepted, like contraception, fertility treatments and organ transplantation.

An important argument is that germline modifications threaten human dignity. The Parliamentary Assembly of the Council of Europe stated that human dignity implies 'the right to inherit a genetic pattern which has not been artificially changed' [80] and also the Council of Europe declared germline modifications to go against human dignity [7]. However, if GLGE is used to correct defects and to restore health in future children, it is difficult to see how this would show a lack of respect for human dignity. A specific interpretation of the dignity argument is linked to the idea that the human species as such should be respected. Related to this idea is the presentation of the human gene pool as a 'common heritage' that concerns the whole of humanity [81]. There are at least two problems here. The first regards the concept of the 'human gene pool' [82]. Mistakenly, the human gene pool seems to be seen as a fixed catalogue of all human genes. It is unclear why the present catalogue should receive a special status. Moreover, for the sake of mankind, the gene pool has to continue to evolve. In addition, the present objection would mean that every mutation in every new person is problematic. To avoid this conclusion, one would have to focus on intentional genomic modifications. However, intentional modifications need not entail a change in the human gene pool. Gene editing could for instance be used to repair or reinsert an already existing gene (i.e. a normal allele). Supposedly, critics want to prevent the (hypothetical) introduction of genes that would alter the person to a point where he or she would have features that no other human being has. This may be a valid argument against genetic enhancement (although the line between treatment and enhancement is difficult to draw, see below), but not against the editing of disease-causing mutations. Apart from the fact that human dignity is a very broad concept and notoriously difficult to define, it looks as if this 
argument cannot serve to condemn all germline gene modifications.

Another objection is that germline intervention would violate the autonomy of future children. Different variants of this objection may be discerned. A first version holds that GLGE would be at odds with the autonomy of children thus edited as they did not consent to having their genome modified [83] nor to being included as research subjects (in clinical trials). Although correct, this is true for all reproduction (including natural reproduction) and it is even theoretically impossible to respect this interpretation of autonomy since there is no person before or at the moment of the decision. A second variant of this objection is that GLGE would undermine (what Joel Feinberg has called) the child's right to an open future [84], in that the child would be pre-determined and pressed into some sort of a 'mould' in order to optimally meet his parents' expectations. This would not only 'instrumentalize' the particular child, but would simultaneously undermine respect for human beings more generally [85]. Again, this criticism may be relevant for at least some (theoretical, even largely unrealistic) types of enhancement (see below), but seems not to apply to editing disease-causing mutations.

A somewhat similar argument is brought forward at the species level: future generations have a right to an unmodified gene pool [86]. For some authors, the issue of germline modification is linked to human rights [87]. Altering fundamental human characteristics may lead to inequality and unjust situations in two ways: either the modified 'people' would be superior to the unmodified people and would be unduly privileged, or the modified 'people' would no longer be considered as human and consequently may be deprived of their human rights. But again, this argument seems to be mostly directed at enhancement and is not relevant when it comes to therapeutic or medical editing of disease-causing mutations.

4.3.2.2 Consequentialist objections These objections and concerns regard the risks of reproductive GLGE. It is important to discern medical (health related) and social risks.

\subsection{Health/medical risks}

The health risks of GLGE concern not just the particular edited (embryo and) future child, but also next generations (in plural). The types of risk are rather diverse (see section 2) and include off-target effects, (antagonistic) pleiotropy, genetic and epi-genetic risks. While recent literature seems to be quite reassuring in that new variants of CRISPR are depicted as having increasingly less off-target effects, at the same time some experts worry that 'CRISPR enthusiasts have their head in the sand' about the safety of editing [88].

There is a strong consensus worldwide that, in view of the many unknowns, including the uncertainty about the reversibility of possible adverse health effects, any clinical GLGE would be at least premature. The question is whether it could ever be sound to apply GLGE clinically and if so on what conditions. In order to reduce health risk for children thus conceived, a combination of measures and safeguards could be considered, including:

- performing adequate pre-clinical research,

- embedding possible future reproductive GLGE in a research trajectory,

- limiting clinical GLGE to causative genes in order to minimize the risk of pleiotropy,

- adding back-up WGS/whole exome sequencing (WES)based PGS (and/or similar prenatal screening), and

- embedding clinical GLGE in long-term follow-up studies, which may be especially important for risk reduction for next generations.

Pre-clinical research There is a strong consensus that clinical GLGE could only be justified after adequate preclinical studies and that more pre-clinical GLGE research is needed [11, 89]. This approach ('patience, not patients') is in line with the general framework for responsible innovation in assisted reproduction as developed by, among others, ESHRE [75] (see section 4.2). Clearly, questions about risk are not just scientific, but also normative. The vexing question remains of when findings of adequate pre-clinical safety studies would be sufficiently reassuring to justify experimental reproductive technologies in general and clinical GLGE in particular-how safe is safe enough? What is the proper evaluation standard for any such risks? Even after extensive, reassuring preclinical safety-research there will always be a residual risk that can only be clarified by engaging in clinical research. A 'zero risk-tolerance' criterion would preclude any clinical innovation (because of its inherent risk) and would be at odds with regular assisted reproduction practice. But what is, then, the appropriate alternative evaluation standard? Obviously, it is important to avoid arbitrary and ad hoc decisions, and to develop a coherent and transparent policy

A clinical research trajectory- Whether we would consider the step towards clinical application of GLGE should depend on the outcomes of basic and pre-clinical research, taking account of further ethical and legal discussion, societal views, risks and implications (see below). If so, this should be embedded in a formal and rigid research trajectory. According to the Clinical Trials Regulation EU No.536/2014, Article 90 "No gene therapy clinical trials may be carried out which result in modifications to the subject's germ line genetic identity" [8]. The implication of this regulation may well be that clinical GLGE research will be impossible in the European 
Union (EU) so that such research takes place outside the EU and without proper research protocols and oversight.

Focus on causative mutations in order to reduce pleiotropic risks- While the debate about the health risks of future clinical GLGE seems to concentrate on off-target effects, the risk of pleiotropy is as important, including antagonistic pleiotropy, meaning that decreasing the risk of developing a particular disease may simultaneously increase the risk of having another disease. Current knowledge of the human genome is rather fragmentary-which is a reason for concern regarding clinical GLGE:

"Pleiotropy may be a widespread phenomenon ..... if antagonistic pleiotropic effects are pervasive then this suggests that we use caution when we design geneticallybased treatments for diseases. ... a full understanding of the risks and benefits of undergoing such gene-targeted treatment is essential to ethical patient care. ... Rather than just focusing on a culprit disease allele and silencing it, selectively inhibiting the allele's deleterious pathway while allowing the beneficial pathway to persist becomes a more responsible, albeit more difficult, course of action" [90].

This risk seems to be of lesser concern when clinical GLGE would involve well-known highly penetrant (causative), clearly pathogenic, mutations linked with Mendelian diseases-but may be more relevant when clinical GLGE would involve alleles linked with complex disorders and traits, caused by less well or not understood gene-environment or gene-gene interactions. In view of this, GLGE of clearly pathogenic mutations can more easily be justified as being proportional than GLGE of less well understood mutations and genetic variants.

Back-up testing- One might consider including WGS/WESbased 'comprehensive' PGS, combined with a trio-analysis, as a safeguard to detect off-target effects (iatrogenic damage) in edited embryos. Clearly, such PGS may simultaneously generate IFs, including both inherited and de novo mutations. The ethics of comprehensive PGS is more complex in a clinical context as compared with using such a safety-test as part of pre-clinical studies (see above). Ethical issues of the former include the feasibility of prospective parents' informed consent, the proper handling of difficult reproductive genetic counselling dilemmas, including possible tensions between transfer criteria and preferences of applicants on the one hand and professionals on the other, and the possible invasion of future children's right to an open future, more in particular their right not to know about their genetic status, i.e. their right to decides themselves, later in life, when competent, about undergoing predictive genetic testing for late(r) onset diseases [91, 92]. In theory, at least some of these issues could be avoided or mitigated by an additional round of GLGE of any IF or off-target effect found-but this scenario seems to be far-fetched. A more realistic scenario (depending on the results of pre-clinical research into possible off-target effects of GLGE) may be to target clinical PGS to possible off-target effects and to then select an unaffected embryo for transfer. Maybe, similar WGS/WES-based screening could alternatively be considered during pregnancy.

Follow-up- Part of the framework for responsible innovation in assisted reproduction is the follow-up of children conceived through new, experimental reproductive technologies $[65,75]$. A fortiori, any future clinical GLGE should be embedded in such follow-up studies. Experience so far with follow-up studies linked with ARTs shows that there are practical barriers and limits in terms of, for example, lack of funding and tensions with parental autonomy and familial and children's privacy, especially when it comes to long-term follow-up, as would be the ideal in this context.

Many critics of GLGE argue that there are safer alternatives, especially PGD or more precisely: PGD combined with a selective transfer of a 'healthy' embryo. In view of these alternatives, it is sometimes questioned as to whether there is a real need for human GLGE (see below).

\subsection{Societal risks and concerns}

There are different types of societal risks and concerns. We will focus here on four of these, two of which are often addressed under the heading of 'eugenics'. As eugenics is a term with very different meanings, we will avoid this term as much as possible and point to specific societal concerns covered by this term [93].

Disability rights- A first concern is that GLGE may have negative consequences for (at least some) people with handicaps and disorders. This concern, which does not regard GLGE specifically, but reproductive and genetic medicine more generally, is often called 'the disability rights critique'. In the background of this critique is the tension between the medical and the social model of disability [94, 95]. While the medical model, aimed at prevention and treatment of disease, is based on an individualistic account of disability that focuses on the biological deficit, the social model stresses societal and cultural co-determinants of disability, like exclusion of people with impairments, environmental barriers to participation, stigmatizing cultural discourse, and discrimination. In recent years, patient organizations (sometimes explicitly under the umbrella of the disability rights movement) have substantially contributed to a public policy agenda aimed at strengthening the societal position, interests and rights of people with disabilities through barrier removal, anti-discrimination legislation and inclusion of people with disabilities. At the same time, patient organizations are very much in favour of research on new therapies. 
The disability rights concern comes in different forms [79]. One is the so-called 'expressivist' argument, holding that genetic interventions, including GLGE, express negative judgments about the worth of the life of people with disabilities, which would violate their right to be regarded as persons of equal standing. Obviously, society should (continue to) protect the equal rights of people with impairments. However, it is difficult to see how this would amount to an argument against developing new (genetic or non-genetic) therapies which may substantially improve their quality of life and avoid serious suffering. A second concern is that both preventive and therapeutic medical interventions, including GLGE, could reinforce the traditional medical model, with its blindness for sociocultural determinants of disability. While a one-dimensional medical approach is, indeed, to be avoided, this is not an argument against developing new treatment options either. A final concern is articulated as the 'loss-of-support' argument, i.e. that to the extent that genetic science, prevention and therapy will lead to reducing the number of disabled people, public and political support for these people will also dwindle. While this concern underlines the continued responsibility of society for also supporting lower numbers of people with particular handicaps, this is again not a good reason to refrain from developing new types of prevention or therapy, such as germline or somatic gene editing. If we would accept the loss-of-support argument, we should also stop current preventative programmes, such as recommending folic acid to pregnant women in order to reduce the risk of neural tube defects-which would be unacceptable.

Some commentators, taking the social model to its extreme, argue that there is no real need to invest in the development of new treatments, genetic or otherwise. In their view it is society that needs to be treated, rather than people with impairments. While it is certainly true that at least part of the problems that many people with impairments encounter could be diminished or even avoided if society were more inclusive of diversity, the problems of people with impairments cannot simply be reduced to prejudice and exclusion. The extreme variant of the social model disregards limitations that cannot be erased in even the most 'barrier-free utopia' [95, 96].

All in all, the disability rights critique forcefully reminds society of its responsibilities towards people with disabilities, more particularly its obligation to remove barriers for inclusion, but it should not be used as an argument against the development of medical therapies, including GE, irrespective of whether it is somatic or germline GE.

The undermining of reproductive autonomy- Concerns have been raised that reproductive GLGE will increase the pressure to avoid the conception of affected/handicapped babies and as a result undermine prospective parents' reproductive freedom. This may happen in different ways: by more or less subtle moral and social pressure or even by legal enforcement (direct coercion). How likely is this scenario, how is to be evaluated and what are the implications for policy-making regarding clinical GLGE?

For evaluating this objection, it is important to place GLGE in the broader context of repro-gene-ethics and options to avoid the birth of (seriously) affected/handicapped children. Although views about prospective parents' responsibility regarding the handling of possible reproductive genetic risk vary widely, there is a strong consensus in ethics that taking reproductive genetic risks is not ethically indifferent and that prospective parents should, in principle, try to avoid at least high risks of serious suffering for future children. This is widely considered to be a moral-not a legal-responsibility. Direct coercion (legal enforcement) to make use of 'preventive' options, such as prenatal testing and selective abortion or PGD, maybe linked with GLGE, would be ethically and legally unjustified-and seems to be rather unlikely, at least in democratic countries respecting human rights. Still, socio-moral pressure to avoid high genetic risks of having a seriously affected child may increase as the possibilities for such avoidance grow. In fact, this is a worry already regularly mentioned and encountered in the context of current repro-genetic options, like making use of donor gametes, prenatal testing and PGD, although there may also be pressure, at least in some cultures and families, to not make use of these options. Importantly, however, this risk is not widely considered to be a convincing objection to the offering of such options. On the contrary, these options are considered valuable first and foremost as they may allow prospective parents to take measures to avoid the conception or birth of seriously affected children in their families. In view of this, and taking account of the fact that GLGE would add only a little to any already existing, more or less subtle, social pressure, it would be problematic and inconsistent to prohibit GLGE in order to protect reproductive autonomy. Instead of selectively and arbitrarily prohibiting a particular technology in order to protect future reproductive freedom, society should uphold and materialize its willingness and commitment to provide adequate medical care and societal support for each and every handicapped baby. Any punishment of parents who conceive a handicapped baby, whose conception and/or birth could have been prevented, by withholding (funding for) adequate medical care of such babies would not only undermine the reproductive confidence and autonomy of prospective parents, it would also be highly unjust to these babies $[97,98]$ and unacceptable at a societal level.

In the context of applying for assisted reproduction, the situation may be somewhat more complex. According to the widely accepted normative framework for genetic counselling and testing in reproduction, the central ethical principle 
is respect for reproductive autonomy. This is made operational by underscoring the importance of both the prerequisite of voluntariness (as part of informed consent) and the ideal of non-directive counselling, which implies that doctors should support prospective parents at high risk of having an affected child, whatever reproductive option they select, preferably after an exploration of what options are available and what their 'considered feelings and views' are in relation to these. This accepted ethical guidance for reproductive genetic counselling is, however, not entirely applicable in the context of assisted reproduction. After all, doctors involved have the professional responsibility to take account of the welfare of the possible future child and to refrain from medically assisted reproduction in case of 'a high risk of serious suffering/harm' to the child [75]. In view of this, it may be morally justified to offer PGD to applicants at high genetic risk of having a seriously affected child as a condition for access to assisted reproduction-a so-called 'coercive' offer [99]. If so, a case could perhaps be made for offering GLGE (instead of PGD aimed at a selective transfer of a 'healthy' embryo) to prospective parents at high genetic risk as a condition for access to assisted reproduction. There may well be different views about whether this would indeed be acceptable-but, even if clearly problematic, this scenario is not a good reason to refrain from offering GLGE (if proven to be safe and effective) at all.

'Enhancement': designer babies- An important concern is the fear that prospective parents (and clinicians/companies) may engage in making so-called designer babies. Like 'eugenics', the terms 'germline enhancement' and 'designer baby' are often not precisely defined. Mostly, the terms seem to refer to modifying/editing the genome of future children for non-medical reasons, or, maybe more precisely, for the improvement of normal traits. Examples often mentioned include raising cognitive skills/IQ, a social attitude/empathy, and exceptional musical and sporting capacities. But strengthening the resistance to diseases or eliminating carrier status for recessive conditions (in situations where being a carrier has no clinical significance for the health of the carrier himself) can also be regarded as forms of enhancement-which illustrates the conceptual blurring of medical and non-medical, preventative and enhancement-like applications [79, 100, 101].

People have different expectations regarding the feasibility of germline enhancement. While 'designer baby' talk plays a major role both in the imagination of the public and in scenarios discussed by policymakers and philosophers/ ethicists (partly as a consequence of the genetic reductionism communicated by many high-profile geneticists in the past), most biomedical experts seem to consider this as science fiction, at least insofar as making a 'designer baby' would require the modification of complex traits. Some recent publications clearly state that even with the most accurate and reliable version of CRISPR, programming favourable traits in human embryos may not be possible [102, 103]. Technology is not the limiting factor in the enhancement of individuals, but rather, so it is argued, it is nature. A trait can be edited in the germline only when two conditions are met. First, the trait must be predominantly determined by DNA-its heritability must be close to $100 \%$. According to a recent review, most potentially desirable traits have a moderate heritability; for example, the heritability of intelligence and higher-level cognitive functioning is around 50\% [104]. Second, for enhancement to be practical, the traits in question must be caused by a single variant or an interaction among a limited number of variants. Although it may become possible to edit DNA accurately at multiple loci, it is unlikely, so the argument continues, that we will learn anytime soon how to successfully edit tens or hundreds of variants simultaneously. GLGE for enhancement purposes should, then, be considered a non-issue: "(...) progress should not be hindered by an ethical debate about a potential misuse of the technology that will not be possible" [102].

Others disagree, however, for different reasons. First, there may well be some not a priori unrealistic examples of enhancement of less complex traits, such as resistance to particular infections. Second, while successfully editing tens or hundreds of variants simultaneously is not a realistic option at the moment, this may well change. And third: some prospective parents may want to make use of CRISPR -if safe and affordable-for more complex normal traits even if a successful programming of the desired trait cannot be guaranteed-a significant increase of the likelihood of the phenotype may be 'good enough' for them to proceed. It is not unrealistic, then, to expect that commercial companies and professional GLGE 'enthusiasts' may want to exploit prospective parents' dreams (or their fears to lag behind) by selling them this technology as a means to at least improve their chances of having a 'perfect child' (however that is understood). Even if the designing is still imperfect, this may be a highly lucrative market (think of the analogy with companies which offer direct-to-consumer tests). Competition for a market share may lead these companies to exaggerate both the heritability of the relevant traits and the probability of the effectiveness of GLGE. They might also see an attractive market in advertising 'smart combinations' of GLGE and life-style modification, thus bypassing any accusations of outdated genetic reductionism.

Ethical evaluations of GLGE enhancement differ, not just because of different normative views, but also because the concepts and examples used differ significantly. In the early days of the debate on GLGE there was an almost unanimous support for the view that we can and should make a sharp distinction, both conceptually and ethically, 
between gene therapy and enhancement, of which only the former could be morally sound [105]. But this strong consensus seems to have disappeared, maybe surprisingly quickly $[101,106]$. So-called 'liberal eugenics', arguing that prospective parents should be largely free to genetically design their future children, has gained considerable support, at least in the academic literature-which is not to say that anything goes. Most commentators who consider the idea of drawing a rigid line between (germline gene) therapy and enhancement to be problematic, both conceptually and ethically, seem to argue in favour of different ethical evaluations of specific types of genetic enhancement. Anticipating a better scientific understanding of the complexity of our genome and further technical developments and breakthroughs in the field of GLGE, it might be helpful to make a distinction between non-medical and medical genetic enhancement, and, with regard to the former, between 'instrumentalizing' and 'non-instrumentalizing' types of genetic enhancement. A more detailed reflection is beyond the scope of this paper (and, in view of the current state of science, highly hypothetical), so we only add a few remarks:

- medical genetic enhancement: an often used example is the strengthening of the human immune system. This, so it is argued, may not be a priori unsound, as it is linked with the classical aim(s) of medicine and may in fact be comparable with traditional vaccination. A second example would be the editing of embryos carrying recessive conditions. While some authors seem to simply assume that this would be ethically sound [107], others would probably dismiss this as a problematic form of population eugenics.

- non-medical genetic enhancement: this is widely considered to be ethically unsound. Major objections are that this would be at odds with human dignity, would instrumentalize the child and undermine its right to an open future $[85,96,108]$. But some scholars argue that non-medical germline GLGE would not necessarily instrumentalize the future child and should not be categorically dismissed. Some traits are, so it is argued, 'general purpose' means i.e. capacities that are useful and valuable in carrying out nearly any plan of life or set of aims that humans typically have [79, 109]. A good example is intelligence; a genetically (or otherwise) enhanced IQ would not limit the child's right to an open future.

Even if the reasoning behind the latter view is sound, there are additional issues to be addressed-apart from the fact that precisely the example of genetically enhancing IQ is, because of the complexity of this trait, qualified by most genetic experts as totally unrealistic. One further issue is the need to take account of the possible implications of the phenomenon of pleiotropy, especially antagonistic pleiotropy. This is a more relevant issue in the context of possible GLGE of complex traits than when it is about GLGE of causative genes with a clear pathogenic effect (see above). Taking pleiotropic risks can be more easily considered to be proportional when it is linked with avoiding a serious disease than when it is merely about enhancing a normal, healthy future child.

No doubt, these conceptual and normative issues require a more detailed analysis and debate. For the moment, it is important to acknowledge that any enhancement-oriented GLGE of complex traits is far beyond what may become possible in the next few years or even decades-and may never become a realistic option. That said, at least two policy questions are on the agenda right now. First, how do we tackle the risk of commercial exploitation of uninformed, naïve, parental dreams about perfect children? Second, is it acceptable or wise to take the slippery slope-risk that allowing GLGE, even if only for serious disorders, will in the end (irrespective of well-intended mechanisms to avoid this, like strict criteria/indications and procedures for societal oversight of GLGE-practice) result in all sorts of germline enhancements? This question, like the question mentioned previously regarding the ethical evaluation of residual health risks of possible future clinical GLGE, should be addressed taking account of another question: what is the added value of GLGE, in view of the currently available therapeutic and reproductive alternatives (see below)?

Inequity- GLGE will in most scenarios be a very expensive procedure. Even if the gene editing in itself may not necessarily be expensive, the accompanying steps (IVF, PGD, safety measures, etc.) most likely will be. This raises the question of who will have access to the technology. This question is raised for every emerging technique and should be considered within the context of the distribution of scarce resources. The inclusion or exclusion of an ART procedure in a decent package of reimbursed health care will depend on the wealth of the state and on the status attributed to infertility. At the moment, some countries have generous provisions for medically assisted reproduction while others largely leave this to the private market. However, all countries have limits for the spending of public resources on infertility treatment (e.g., female age, number of cycles). These limits are justified by different criteria: efficiency, cost-effectiveness and safety. The same criteria could be used for the decision regarding the reimbursement of GLGE. Three general remarks may be sufficient for the moment. First, decisions on reimbursement and access could be made in steps. One could for instance at the start only provide reimbursement for certain types of diseases. Second, most affluent societies strive to give equal access to medical care for everyone. 
That does not mean that when equity is not reached, no one should have access to the treatment. This 'levelling down' justice would in fact block all progress in medicine. Third, affordability may also to a large extent depend on patenting and commercialization of the technique [110].

Beside the matter of access based on financial means, there is a second justice consideration that refers to prioritization of diseases. Here too, several criteria can be used: magnitude and frequency of need, cost-effectiveness, the existence of alternative interventions, etc. [89]. The experience with the introduction of other techniques, such as PGD, may help to design a strategy here.

Likewise, GLGE 'enhancements' to subsets of the population could exacerbate social inequities-although this threat may be somewhat exaggerated in view of the serious scientific doubts about the feasibility of most, rather theoretical, GLGE-enhancements.

\subsubsection{Alternatives for reproductive GLGE: 'no real need' for the latter?}

In view of both the medical and societal objections and concerns, alternative options should be taken into account for parents 'at high risk' of having an affected child and who do not wish to have children affected by the specific condition they are at risk for. The alternatives may be of two different types: first, therapeutic (postnatal)/non-reproductive, and second, reproductive. The most obvious therapeutic alternative may be somatic GLGE. Reproductive alternatives include adoption, prenatal diagnosis, the use of donor gametes and (IVF/ICSI) PGD aimed at transferring a 'healthy' embryo. The availability of possible alternatives seems to strengthen the reluctance and opposition to future reproductive GLGE [100, 111]: 'there is no real need to engage in germline GE' [112]. But what about the effectivity and availability of these alternatives? And does the balancing of the pros and cons of these alternatives indeed lead to the conclusion that these are to be ethically preferred?

While expectations regarding the effectiveness and future clinical utility of somatic GE seem to increase, (safe and effective) GLGE could have two comparative advantages: it is more efficient because of its multi-generational preventive/therapeutic potential, and it may be more effective for the prevention/therapy of multi-organ disorders, at least in theory. For at least a subset of such genetic disorders, somatic GLGE is simply not a realistic option. Somatic GE may become an effective treatment for less complex (single organ) disorders, and preferred by many, even if GLGE would prove to be safe and effective. But, obviously, context matters. If, for example, prospective parents at high genetic risk are sub-fertile and apply for IVF/ICSI anyway, their fertility treatment might be relatively easy combined with GLGE, if safe and effective, instead of anticipating repeated somatic GE in consecutive generations.

With regard to reproductive alternatives several issues need further discussion, including:

- Many prospective parents at high genetic risk do not meet the stringent criteria for adopting a child, as accepted in the relevant jurisdictions. Maybe these criteria could be relaxed-but even then, this may not be a real, let alone the ideal, solution for at least some prospective parents;

- Most prospective parents prefer to have a genetically related child-adoption or donor gametes are either not an option at all (the use of donor gametes is forbidden in many countries) or only second best. How to morally evaluate this preference? Obviously, this is a fundamental question that concerns reproductive medicine generally. Even if one would argue that counselling might help prospective parents to reconsider their preference ('people can be very happy without having children', and/or 'children need not be genetically linked in order to build a happy family'), to disregard people's persistent preferences for a genetically linked child would be difficult to justify in view of the principle of respect for reproductive autonomy. Still, a further debate about the (relativity of the) value of 'genetic parenthood' is important.

There is no doubt that PGD aimed at a selective transfer of an unaffected embryo can and does help many prospective parents 'at high genetic risk' to have a (genetically related) unaffected child. To argue, however, that therefore GLGE is not really needed, is a non sequitur:

- In some (admittedly rare) cases, prospective parents can only have affected children, for example, when both partners are affected by the same autosomal recessive disorder. PGD is, then, a priori pointless.

- Instead of routinely discarding affected PGD-embryos, a differentiated ranking system may be preferable, which prioritizes unaffected embryos for transfer while cryopreserving the (good morphology) affected embryo(s) for a possible thawing, editing (if safe and effective) and transfer in a next cycle. This policy may well increase the take-home-baby-rate of IVF/ICSI-PGD cycles and be more patient-friendly.

- Furthermore, in a significant number of cases, all embryos in a given IVF/ICSI-PGD cycle lack the criteria for transfer, either because they all prove to be affected (think especially of so-called 'combination PGD', performed for two indications), or because the embryos prove to be unaffected, but not a good match for a diseased sib needing hematopoietic stem cells (in the context of PGD/ 
HLA-typing, aimed at conceiving a health 'saviour' baby). The couple may then engage in a new cycle or consider transferring an affected embryo or an HLA-mismatched embryo. If effective and safe GLGE becomes possible in the future, an additional IVF/ICSI-PGD cycle would be disproportional in view of its (avoidable) burdens and risks (and costs). And wouldn't the transfer of an affected embryo be unsound if one could avoid the birth of an affected child by GLGE?

- For a comparative moral evaluation of 'standard' PGD and (PGD combined with) GLGE, some deontological aspects may be relevant as well. First, as 'standard' PGD aiming at a selective transfer entails the de-selection (and destruction) of embryos, while GLGE may (avoid or) at least reduce embryo loss, the latter strategy may be the morally better one (if safe and effective and) if one acknowledges that the embryo has a significant moral status -which is not necessarily to be identified with a strict 'pro-life' view. Second, if prospective parents prefer reasonably safe and effective GLGE instead of PGD aimed at a selective transfer, to not accept this may be at odds with respect for reproductive autonomy.

\subsubsection{Comprehensive PGS: a driver for systematic GLGE?}

Assuming further technological improvements, comprehensive PGS, making use of high-resolution sequencing technology, could be used not only as an instrument in basic and pre-clinical GLGE research (see section 4.1 and 4.2 ) and as a safeguard in possible future clinical GLGE (see section 4.3.2), but also it might be (routinely) used in the context of future regular IVF. In fact, the latter is sometimes advocated in the medical literature for selecting 'the best embryo' for transfer. Such PGS-which raises a lot of ethical issues (see section 4.3.2) [91, 92]-might then function as a powerful 'driver' for clinical GLGE, if proven to be safe, effective and applicable to day 3 or even day 5 embryos; it might be argued that all embryos, like all humans, are 'fellow mutants' and will prove to be 'affected' or 'at risk' in different ways, being among others heterozygous for some recessive conditions, and carrying predispositions for more or less common disorders, polymorphisms, and genetic variants. The challenge may then become to find and edit the embryo with the 'best' risk profile, which would push the application of GLGE far beyond the 'high risk of serious disease'-cases where it is regularly considered to be possibly sound in current ethical literature. Especially private clinics and clinics in countries with a lack of adequate regulation may want to (commercially) offer routine comprehensive PGS combined with gene editing of any 'defect' found. Obviously, this scenario would be problematic in view of the pleiotropic risks of GLGE, as these can be more easily considered to be proportional if linked to avoiding a serious disease than when it is just about editing lower risk factors or, particularly, enhancing a normal, healthy future child. But at the same time, this scenario urges society even more strongly (than GLGE of one particular disease characteristic) to engage in a more principled debate about the ethics of, and policymaking regarding, the conceptually and morally grey area between therapeutic, preventive, and enhancing GLGE.

\section{Recommendations}

Based on this overview of the ethical and legal considerations, ESHG and ESHRE consider it to be their professional responsibility to contribute to further discussion on GLGE. Based on this Background document, Recommendations have been developed and discussed within both societies $[12,13]$. We encourage other stakeholders to also engage in this debate.

\section{Summary}

What does this study mean for the patients?

- This paper is the background to Recommendations from the European Society of Human Reproduction and Embryology (ESHRE) and the European Society of Human Genetics (ESHG), which considers the issue of gene editing of sperm, oocytes or embryos.

- Editing the genetic make-up of sperm, oocytes or embryos has the potential to help people with hereditary diseases, but there are currently many legal barriers to this across Europe. There are also many ethical questions as this type of gene editing would lead to hereditary genetic changes being passed down from one generation to the next. This would have potential benefits for people suffering from inherited conditions, but more research is needed to ensure it would be safe and effective and there is still much ethical debate about such research itself.

- The paper summarizes the different ethical objections, legal barriers, research issues and practical problems which currently prevent this type of gene editing being used and provides a background briefing for the Recommendations the two Societies have made.

Acknowledgements The authors thank the persons who commented on earlier versions of the Recommendations or the Background document to the Recommendations, especially the members of the Public and Professional Policy Committee of ESHG and the Ethics Committee of ESHRE and Erika Kleiderman, Bartha Maria Knoppers, 
Raul Piña-Aguilar, Alessandra Renieri, Gijs Santen and Kirmo Wartiovaara.

Author contributions GdW wrote the Introduction, the section on Legal regulations and the section on Ethics; MC co-authored the Introduction; WD co-authored the section on Legal regulations; GP coauthored section 4.3.2.1; $\mathrm{BH}$ wrote the section on Scientific developments and expectations, with input from AC, UE-R, and DR. All other co-authors participated in one or more tele-conferences or meetings to discuss the draft, reviewed the article and made corrections and suggestions for improvement

Funding No external funding was obtained. Costs for the meetings were covered by ESHRE and the ESHG.

\section{Compliance with ethical standards}

Conflict of interest The authors declare that they have no conflict of interest.

Open Access This article is licensed under a Creative Commons Attribution-NonCommercial-ShareAlike 4.0 International License, which permits any non-commercial use, sharing, adaptation, distribution and reproduction in any medium or format, as long as you give appropriate credit to the original author(s) and the source, provide a link to the Creative Commons license, and indicate if changes were made. If you remix, transform, or build upon this article or a part thereof, you must distribute your contributions under the same license as the original. The images or other third party material in this article are included in the article's Creative Commons license, unless indicated otherwise in a credit line to the material. If material is not included in the article's Creative Commons license and your intended use is not permitted by statutory regulation or exceeds the permitted use, you will need to obtain permission directly from the copyright holder. To view a copy of this license, visit http://creativecommons. org/licenses/by-nc-sa/4.0/.

\section{References}

1. Ledford $\mathrm{H}$. Riding the CRISPR wave. Biologists are embracing the power of gene-editing tools to explore genomes. Nature. 2016;531:156-9.

2. Qasim W, Zhan H, Samarasinghe S, et al. Molecular remission of infant B-ALL after infusion of universal TALEN gene-edited CAR T cells. Sci Transl Med. 2017;9:eaaj2013.

3. Cyranoski D. CRISPR gene-editing tested in a person for the first time. Nature. 2016;539:479.

4. European Medicines Agency. Issues identified by stakeholders: follow-up from EMA's ATMP workshop. http://www.ema. europa.eu/docs/en_GB/document_library/Other/2017/02/ WC500220952.pdf. Accessed14 June 2017.

5. Howard H, van El CG, Forzano F, et al. One small edit for humans, one giant edit for humankind? Points and questions to consider for a responsible way forward for gene editing in humans. Eur J Hum Genet. 2017 Nov 30. 10.1038/s41431017-0024-z [Epub ahead of print]

6. Isasi R, Kleiderman E, Knoppers BM. Editing policy to edit the genome? Science. 2016;351:337-9.

7. Council of Europe. Convention for the protection of human rights and dignity of the human being with regard to the application of biology and medicine: convention on human rights and biomedicine. Oviedo, 4.IV.1997. https://www.coe.int/en/web/ conventions/full-list/-/conventions/treaty/164. Accessed14 June 2017.

8. Regulation No. 536/2014 of the European Parliament and the Council of 16 April 2014 on clinical trials on medicinal products for human use, and repealing Directive 2001/20/EC. https://ec. europa.eu/health/sites/health/files/files/eudralex/vol-1/reg_2014_ 536/reg_2014_536_en.pdf. Accessed 14 June 2017.

9. Reardon S. Global summit reveals divergent views on human gene editing. Nature. 2015;528:173.

10. Reardon S US science advisers outline path to genetically modified babies. Nature 2017; https://doi.org/10.1038/nature. 2017.21474

11. The National Academies of Sciences, Engineering, and Medicine. Human Genome Editing: Science, Ethics, and Governance 2017. http://nationalacademies.org/gene-editing/consensusstudy/index.htm. Accessed 14 June 2017.

12. De Wert G, Pennings G, Clarke A, et al. Human germline gene editing. Recommendations of the European Society of Human Genetics and the European Society of Human Reproduction and Embryology. Eur J Hum Genet. (In press/ submitted).

13. De Wert G, Pennings G, Clarke A, et al. Human germline gene editing. Recommendations of the European Society of Human Genetics and the European Society of Human Reproduction and Embryology. Human Reproduction Open. (In press/ submitted)

14. Vassena R, Heindryckx B, Peco R, et al. Genome engineering through CRISPR/Cas9 technology in the human germline and pluripotent stem cells. Hum Reprod Update. 2016;22:411-9.

15. Zhou X, Xin J, Fan N, et al. Generation of CRISPR/Cas9mediated gene-targeted pigs via somatic cell nuclear transfer. Cell Mol Life Sci. 2015;72:1175-84.

16. Yoshimi K, Kaneko T, Voigt B, et al. Allele-specific genome editing and correction of disease-associated phenotypes in rats using the CRISPR-Cas platform. Nat Commun. 2014;5:4240.

17. Heo YT, Quan X, Xu YN, et al. CRISPR/Cas9 nucleasemediated gene knock-in in bovine-induced pluripotent cells. Stem Cells Dev. 2015;24:393-402.

18. Han H, Ma Y, Wang T, et al. One-step generation of myostatin gene knockout sheep via the CRISPR/Cas9 system. Front Agr Sci Eng. 2014;1:2-5.

19. Kang Y, Zheng B, Shen B, et al. CRISPR/Cas9-mediated Dax1 knockout in the monkey recapitulates human AHC-HH. Hum Mol Genet. 2015;24:7255-64.

20. Wu Y, Liang D, Wang Y, et al. Correction of a genetic disease in mouse via use of CRISPR-Cas9. Cell Stem Cell. 2013;13:659-62.

21. Long C, McAnally JR, Shelton JM, Mireault AA, Bassel-Duby $\mathrm{R}$, Olson EN. Prevention of muscular dystrophy in mice by CRISPR/ Cas9-mediated editing of germline DNA. Science. 2014;345:1184-8.

22. Niu Y, Shen B, Cui Y, et al. Generation of gene-modified cynomolgus monkey via Cas9/RNA-mediated gene targeting in one-cell embryos. Cell . 2014;156:836-43.

23. Liu H, Chen Y, Niu Y, et al. TALEN-mediated gene mutagenesis in rhesus and cynomolgus monkeys. Cell Stem Cell. 2014; 14:323-8.

24. Liu Z, Zhou X, Zhu Y, et al. Generation of a monkey with MECP2 mutations by TALEN-based gene targeting. Neurosci Bull. 2014;30:381-6.

25. Araki M, Ishii T. International regulatory landscape and integration of corrective genome editing into in vitro fertilization. Reprod Biol Endocrinol. 2014;12:108.

26. Ran FA, Hsu PD, Lin CY, et al. Double nicking by RNA-guided CRISPR Cas9 for enhanced genome editing specificity. Cell. 2013;154:1380-9. 
27. Liang $\mathrm{P}, \mathrm{Xu} \mathrm{Y}$, Zhang $\mathrm{X}$, et al. CRISPR/Cas9-mediated gene editing in human tripronuclear zygotes. Protein Cell. 2015;6:363-72.

28. Kang X, He W, Huang $\mathrm{Y}$, et al. Introducing precise genetic modifications into human 3PN embryos by CRISPR/Cas-mediated genome editing. J Assist Reprod Genet. 2016;33:581-8.

29. Shen B, Zhang J, Wu H, et al. Generation of gene-modified mice via Cas9/RNA-mediated gene targeting. Cell Res. 2013;23:720-3.

30. Yang H, Wang H, Shivalila CS, et al. One-step generation of mice carrying reporter and conditional alleles by CRISPR/Cas mediated genome engineering. Cell. 2013;154:1370-9.

31. Yen ST, Zhang M, Deng JM, et al. Somatic mosaicism and allele complexity induced by CRISPR/Cas9 RNA injections in mouse zygotes. Dev Biol. 2014;393:3-9.

32. Chen S, Lee B, Lee AY, Modzelewski AJ, He L. Highly efficient mouse genome editing by CRISPR ribonucleoprotein electroporation of zygotes. J Biol Chem. 2016;291:1457-67.

33. Hashimoto M, Yamashita Y, Takemoto T. Electroporation of Cas9 protein/sgRNA into early pronuclear zygotes generates non-mosaic mutants in the mouse. Dev Biol. 2016;418:1-9.

34. Ma H, Marti-Gutierrez N, Park SW, Wu J, Lee Y, Suzuki K, Koski A, Ji D, Hayama T, Ahmed R, Darby H, et al. Correction of a pathogenic gene mutation in human embryos. Nature 2017, Aug 2. Epub ahead of print, 10.1038/nature23305.

35. Boel A, Steyaert W, De Rocker N, et al. BATCH-GE: batch analysis of next-generation sequencing data for genome editing assessment. Sci Rep. 2016;6:30330.

36. Goossens E, Van Saen D, Tournaye H. Spermatogonial stem cell preservation and transplantation: from research to clinic. Hum Reprod. 2013;28:897-907.

37. Woods DC, Tilly JL. Isolation, characterization and propagation of mitotically active germ cells from adult mouse and human ovaries. Nat Protoc. 2013;8:966-88.

38. Hanna J, Cheng AW, Saha K, et al. Human embryonic stem cells with biological and epigenetic characteristics similar to those of mouse ESCs. Proc Natl Acad Sci USA. 2010;107:9222-7.

39. Duggal G, Warrier S, Ghimire S, et al. Alternative routes to induce naïve pluripotency in human embryonic stem cells. Stem Cells. 2015;33:2686-98.

40. Van der Jeught M, O’Leary T, Duggal G, De Sutter P, Chuva de Sousa Lopes S, Heindryckx B. The post-inner cell mass intermediate: implications for stem cell biology and assisted reproductive technology. Hum Reprod Update. 2015;21:616-26.

41. Hayashi K, Ohta H, Kurimoto K, et al. Reconstitution of the mouse germ cell specification pathway in culture by pluripotent stem cells. Cell. 2011;146:519-32.

42. Hayashi K, Ogushi S, Kurimoto K, Shimamoto S, Ohta H, Saitou M. Offspring from oocytes derived from in vitro primordial germ cell-like cells in mice. Science. 2012;338:971-5.

43. Zhou Q, Wang M, Yuan Y, et al. Complete meiosis from embryonic stem cell-derived germ cells in vitro. Cell Stem Cell. 2016;18:330-40.

44. Hikabe O, Hamazaki N, Nagamatsu G, et al. Reconstitution in vitro of the entire cycle of the mouse female germ line. Nature. 2016;539:299-303.

45. Hyslop LA, Blakeley $\mathrm{P}$, Craven L, et al. Towards clinical application of pronuclear transfer to prevent mitochondrial DNA disease. Nature. 2016;534:383-6.

46. Bacman SR, Williams SL, Pinto M, Peralta S, Moraes CT. Specific elimination of mutant mitochondrial genomes in patient-derived cells by mitoTALENs. Nat Med. 2013;19: 1111-3.

47. Jo A, Ham S, Lee GH, et al. Efficient mitochondrial genome editing by CRISPR/Cas9. Biomed Res Int. 2015;2015: 305716 .
48. Diot A, Dombi E, Lodge $\mathrm{T}$, et al. Modulating mitochondrial quality in disease transmission: towards enabling mitochondrial DNA disease carriers to have healthy children. Biochem Soc Trans. 2016;44:1091-100.

49. Yamada M, Emmanuele V, Sanchez-Quintero MJ, et al. Genetic drift can compromise mitochondrial replacement by nuclear transfer in human oocytes. Cell Stem Cell. 2016;18: 749-54.

50. Zhang J, Liu H, Luo S, et al. Live birth derived from oocyte spindle transfer to prevent mitochondrial disease. Reprod Biomed Online. 2017;34:361-8.

51. Reddy P, Ocampo A, Suzuki K, et al. Selective elimination of mitochondrial mutations in the germline by genome editing. Cell. 2015;161:459-69.

52. Irie N, Weinberger L, Tang WW, et al. SOX17 is a critical specifier of human primordial germ cell fate. Cell. 2015;160:253-68.

53. The Francis Crick Institute. Use of CRISPR-Cas9 genome editing technique in human embryos, 2016. https://www.crick.ac.uk/ research/a-z-researchers/researchers-k-o/kathy-niakan/hfealicence/. Accessed 18 June 2017.

54. Kashir J, Heindryckx B, Jones C, De Sutter P, Parrington J, Coward K. Oocyte activation, phospholipase $\mathrm{C}$ zeta, and human infertility. Hum Reprod Update. 2010;16:690-703.

55. Kashir J, Konstantinidis M, Jones C, et al. Characterization of two heterozygous mutations of the oocyte activation factor phospholipase $\mathrm{C}$ zeta (PLC $\zeta$ ) from an infertile man by use of minisequencing of individual sperm and expression in somatic cells. Fertil Steril. 2012;98:423-31.

56. McCoy RC, Demko Z, Ryan A, et al. Common variants spanning PLK4 are associated with mitotic-origin aneuploidy in human embryos. Science. 2015;348:235-8.

57. Belgisch Staatsblad [Law regarding research on embryos in vitro, in Dutch and French]. Volksgezondheid, Veiligheid van de Voedselketen en Leefmilieu. 11 May 2003. http://www.ejustice. just.fgov.be/eli/loi/2003/05/11/2003022592/moniteur. Accessed 17 July 2017.

58. Health Council of the Netherlands: Nuclear transplantation in cases of mutations in mitochondrial DNA. The Hague: Health Council of the Netherlands, 2001; publication no. 2001/07. https://www.gezondheidsraad.nl/en/task-and-procedure/areasof-activity/optimum-healthcare/nuclear-transplantation-in-casesof. Accessed 18 June 2017

59. Nuffield Council on Bioethics. Novel techniques for the prevention of mitochondrial DNA disorders: an ethical review. London: Nuffield Council on Bioethics; 2012. https://nuffieldbioethics.org/wpcontent/uploads/2014/06/Novel_techniques_for_the_prevention_of_ mitochondrial_DNA_disorders_compressed.pdf. Accessed 18 June 2017

60. Castro RJ. Mitochondrial replacement therapy: the UK and US regulatory landscapes. J Law Biosci. 2016;3:726-35.

61. Wolf DP, Mitalipov N, Mitalipov S. Mitochondrial replacement therapy in reproductive medicine. Trends Mol Med. 2015;21:68-76.

62. Dondorp WJ, Bolhuis P Mitochondriale ziekten: celkerntransplantatie en de embryowet. Tijdschrift voor Gezondheidsrecht 2002;26:2-9.

63. Staatsblad, [Embryo Act, in Dutch] 20 June 2002, http://wetten. overheid.nl/BWBR0013797/2013-09-27. Accessed 17 July 2017

64. Dyson A, Harris J, eds. Experiments on embryos. London/New York: Routledge; 1990.

65. Health Council of the Netherlands: Committee on In vitro fertilization. IVF-related research. Rijswijk, 1998; publication no.1998/08E. ISBN 90-5549-225-6. https://www. gezondheidsraad.nl/en/task-and-procedure/areas-of-activity/ 
optimum-healthcare/ivf-related-research. Accessed 18 June 2017.

66. Green RM. The human embryo research debates. Bioethics in the vortex of controversy. Oxford: University of Oxford Press; 2001.

67. De Wert G, Mummery C. Human embryonic stem cells: research, ethics and policy. Hum Reprod. 2003;18:672-82.

68. Dondorp W, De Wert G. Embryonic stem cells without moral pain? The Hague: Health Council of the Netherlands; 2005.

69. ESHRE Task Force on Ethics and Law. The moral status of the pre-implantation embryo. Hum Reprod. 2001;16:1046-8.

70. Pera M, De Wert G, Dondorp W, et al. What if stem cells turn into embryos in a dish? Nat Methods. 2015;12:917-9.

71. Hyun I, Wilkerson A, Johnston J. Revisit the 14-day rule. Nature. 2016;533:169-71.

72. ESHRE Task Force on Ethics and Law. Pennings G, de Wert G, Shenfield F, et al. Oocyte donation for non-reproductive purposes. Hum Reprod. 2007;22:1210-3.

73. Hehir-Kwa JY, Claustres M, Hastings RJ, et al. Towards a European consensus for reporting incidental findings during clinical NGS testing. Eur J Hum Genet. 2015;23:1601-6.

74. Health Council of the Netherlands. Incidental findings made during diagnosis in patient care. The Hague: Health Council of the Netherlands; 2014. https://www.gezondheidsraad.nl/en/ta sk-and-procedure/areas-of-activity/optimum-healthcare/incidenta 1-findings-made-during-diagnosis-in. Accessed 18 June 2017

75. ESHRE Task Force on Ethics and Law. Pennings G, de Wert G, Shenfield F, et al. The welfare of the child in medically assisted reproduction. Hum Reprod. 2007;22:2585-8.

76. McLaren A. IVF: regulation or prohibition? Nature. 1989;342:469-70.

77. Savulescu J, Pugh J, Douglas T, Gyngell C. The moral imperative to continue gene editing research in human embryos. Protein Cell. 2015;6:476-9.

78. Sugarman J. Ethics and germline gene editing. EMBO Rep. 2015;16:879-80.

79. Buchanan A, Brock DW, Daniels N, Wikler D. From chance to choice. Genetics \& Justice. Cambridge: Cambridge University Press; 2000.

80. Parliamentary Assembly of the Council of Europe (1982) Recommendation 934 on genetic engineering. http://assembly. coe.int/nw/xml/XRef/Xref-XML2HTML-en.asp?fileid= 14968\&lang=ent. Accessed 18 June 2017.

81. UNESCO International Bioethics Committee. Report of the IBC on Updating its reflection on the human genome and human rights. Paris, 2 October 2015. http://unesdoc.unesco.org/images/ 0023/002332/233258E.pdf Accessed 18 June 2017.

82. Juengst ET. "Alter-ing" the human species? Misplaced essentialism in science policy. In: Rasko JEJ, O'Sullivan GM, Ankeny RA, (eds.). The ethics of inheritable genetic modification: a dividing line? Cambridge, UK: Cambridge University Press; 2006. p. 149-58.

83. Collins, FS (2015). Statement on NIH funding of research using gene-editing technologies in human embryos. National Institutes of Health. https://www.nih.gov/about-nih/who-we-are/nihdirector/statements/statement-nih-funding-research-using-geneediting-technologies-human-embryos. Accessed 18 June 2017.

84. Feinberg J. The child's right to an open future. In: Aiken W, LaFollette H, (eds.). Whose child? Children's rights, parental authority and state power. Totowa NJ: Rowman \& Littlefield; 1980. p. 124-53.

85. Habermas J. The future of human nature. Cambridge, UK: Polity Press; 2003.

86. Frankel MS, Chapman A. Human inheritable genetic modifications: assessing scientific, ethical, religious and policy issues;
2000. https://www.aaas.org/sites/default/files/migrate/uploads/ germline.pdf. Accessed 18 June 2017.

87. Annas G, Andrews L, Isasi R. Protecting the endangered human: toward an international treaty prohibiting cloning and inheritable alterations. Am J Law Med. 2002;28:151-78.

88. Begley J Do CRISPR enthusiasts have their head in the sand about the safety of gene editing? https://www.statnews.com/ 2016/07/18/crispr-off-target-effects/ Accessed 18 June 2017.

89. Hinxton Group. Statement on Genome Editing Technologies and Human Germline Genetic Modification. 2015. http://www. hinxtongroup.org/hinxton2015_statement.pdf. Accessed 18 June 2017.

90. Carter AJR, Nguyen AQ. Antagonistic pleiotropy as a widespread mechanism for the maintenance of polymorphic disease alleles. BMC Med Genet. 2011;12:160.

91. De Wert G. Preimplantation genetic testing: normative reflections. In: Harper J, (ed.). Preimplantation genetic diagnosis. Cambridge: Cambridge University Press; 2009. p. 259-273.

92. Hens K, Dondorp W, Geraedts J, De Wert G. Comprehensive pre-implantation genetic screening: ethical reflection urgently needed. Nat Rev Genet. 2012;13:676-7.

93. Paul DB. What was wrong with Eugenics? Conflicting narratives and disputed interpretations. Sci \& Educ. 2014;23:259-71.

94. Parens E, Asch Aeds. Prenatal testing and disability rights. Washington: Georgetown University Press; 2000.

95. Shakespeare T. Disability Rights and Wrongs revisited. 2nd edn. Oxford: Routledge; 2014.

96. Davis DS. Genetic dilemmas. Reproductive technology, parental choices and children's futures. 2nd edn. Oxford: Oxford University Press; 2010.

97. De Wert G, De Wachter G. Mag ik uw genenpaspoort? Ethische aspecten van dragerschapsonderzoek bij de voortplanting. Baarn: Uitgeverij Ambo; 1990. (in Dutch)

98. Dondorp W, De Wert G, Bombard Y, et al. Non-invasive prenatal testing for aneuploidy and beyond: challenges of responsible innovation in prenatal screening. On behalf of the European Society of Human Genetics (ESHG) and the American Society of Human Genetics (ASHG). Eur J Hum Genet. 2015;23:1438-50.

99. ESHRE Task Force on Ethics and Law. De Wert G, Dondorp W, Pennings G, et al. Intrafamilial medically assisted reproduction. Hum Reprod. 2011;26:504-9.

100. Health Council of the Netherlands. Heredity: Science and Society; on the possibilities and limits of genetic testing and gene therapy. The Hague: Health Council of the Netherlands; 1989. https://www.gezondheidsraad.nl/en/task-and-procedure/areasof-activity/optimum-healthcare/heredity-science-and-society-onthe. Accessed 17 July 2017

101. Comfort N. The science of human perfection. How genes became the heart of American medicine. New Haven \& London, UK: Yale Univ. Press; 2012.

102. Janssens ACJW Forget about designer babies- gene editing won't work on complex traits like intelligence. The Conversation. December 3, 2015. http://theconversation.com/forget-aboutdesigner-babies-gene-editing-wont-work-on-complex-traits-likeintelligence-51557. Accessed 19 June 2017.

103. Janssens ACJW. Designing babies through gene editing: science or science fiction? Genet Med. 2016;18:1186-7.

104. Polderman TJ, Benyamin B, De Leeuw CA, et al. Meta-analysis of the heritability of human traits based on fifty years of twin studies. Nat Genet. 2015;47:702-9.

105. Anderson WF. Human gene therapy: why draw a line? J Med Philos. 1989;14:681-93.

106. Harris J. Enhancing evolution. The ethical case for making better people. Princeton, USA: Princeton University Press; 2010. 
107. Wivel NA, Walters L. Germ-line gene modification and disease prevention: some medical and ethical perspectives. Science. 1993;262:533-8.

108. Sandel M. The case against perfection. Ethics in the age of genetic engineering. Cambridge, USA: The Belknap Press of Harvard University Press; 2007.

109. Glover J. Choosing children. The ethical dilemmas of genetic intervention. Oxford, UK: Clarendon Press; 2006.
110. Newson A, Wrigley A. Being human: the ethics, law, and scientific progress in genome editing. Aust Q. 2016;87: 3-8.

111. Von den Daele W. Mensch nach Mass? Ethische Probleme der Genmanipulation und Gentherapie. Munchen, Germany: Beck Verlag; 1985. (in German)

112. Mertes H, Pennings G. Modification of the embryo's genome: more useful in research than in the clinic. Am $\mathrm{J}$ Bioeth. 2015;15:52-53.

\section{Affiliations}

\section{Guido De Wert ${ }^{1}$ - Björn Heindryckx ${ }^{2}$ - Guido Pennings ${ }^{3}$ - Angus Clarke $\mathbb{I}^{4}$ - Ursula Eichenlaub-Ritter ${ }^{5}$. Carla G. van $\mathrm{El}^{6} \cdot$ Francesca Forzano $^{7} \cdot$ Mariëtte Goddijn $^{8} \cdot$ Heidi C. Howard ${ }^{9} \cdot$ Dragica Radojkovic $^{10}$. Emmanuelle Rial-Sebbag ${ }^{11} \cdot$ Wybo Dondorp $\mathbb{1}^{1} \cdot$ Basil C. Tarlatzis ${ }^{12} \cdot$ \\ Martina C. Cornel ${ }^{6}$ On behalf of the European Society of Human Genetics and the European Society of Human Reproduction and Embryology}

1 Department of Health, Ethics and Society, Research Institutes GROW and CAPHRI, Faculty of Health, Medicine and the Life Sciences, Maastricht University, Maastricht, The Netherlands

2 Ghent-Fertility and Stem cell Team (G-FaST), Department for Reproductive Medicine, Ghent University Hospital, Ghent, Belgium

3 Bioethics Institute Ghent, Department of Philosophy and Moral Science, Ghent University, Ghent, Belgium

4 School of Medicine, Cardiff University, Cardiff, UK

5 Institute of Gene Technology/Microbiology, Faculty of Biology, University of Bielefeld, Bielefeld, Germany

6 Department of Clinical Genetics, Section Community Genetics and Amsterdam Public Health Research Institute, VU University Medical Center, Amsterdam, The Netherlands
7 Clinical Genetics Department, Guy's Hospital, Guy's and St Thomas' NHS Foundation Trust, London, UK

8 Center for Reproductive Medicine, Department of Obstetrics and Gynecology, Academic Medical Center, AmsterdamZuidoost, The Netherlands

9 Centre for Research Ethics and Bioethics, Uppsala University, Uppsala, Sweden

10 Laboratory for Molecular Biology, Institute of Molecular Genetics and Genetic Engineering, University of Belgrade, Belgrade, Serbia

11 University Paul Sabatier Toulouse, Toulouse, France

12 1st Department of Obstetrics \& Gynecology, School of Medicine, Aristotle University of Thessaloniki, Thessaloniki, Greece 